\title{
Effects of the Molding Process on Properties of Bamboo Fiber/Epoxy Resin Composites
}

\author{
Jiangjing Shi, a,b Yanping Zou, a,b Wenfu Zhang, ${ }^{\text {a,* and Hong Chen }}{ }^{\mathrm{b}}$ \\ Filament winding is an advanced technology for fabrication of high-performance \\ composites. Pressure-free fabrication can be achieved for non-planar \\ composites with complicated shapes using resin-immersed twisting fibers. In this \\ study, twisted bamboo fiber (TBF) composites were prepared by a filament \\ winding processing (FWP). Short bamboo fiber (SBF), long bamboo fiber (LBF), \\ and TBF composites were prepared by hot pressing (HP) and resin transfer \\ molding (RTM). The results showed that the bamboo fiber/epoxy resin \\ composites were positively related to the fiber size. The bamboo fiber/epoxy \\ resin composites fabricated by FWP exhibited optimal shear performance, while \\ those generated by RTM exhibited optimized bending performance. Dynamic \\ thermomechanical analysis revealed that composites made by FWP had \\ optimized interfaces. The FWP mechanism of bamboo fiber composites was \\ resin immersion and alignment of TBF; upon resin immersion the TBF were \\ coated by resin and could not enter the internal tubes or parenchyma tissues of \\ the TBF. The TBF was aligned by winding equipment. After heated solidification \\ of the resin, several bubble pores were distributed on both sides of the TBF, \\ whose positions remained static over time. The filament winding processing for \\ bamboo fiber composites enhanced their performance and could lead to the \\ applications in bamboo fibers composites.
}

Keywords: Bamboo fiber; Bamboo fiber/epoxy resin composites; Filament winding processing;

Hot pressing; Resin transfer molding

Contact information: a: Zhejiang Academy of Forestry, Hangzhou, Zhejiang, P.R. China, 310023;

b: College of Furnishings and Industrial Design, Nanjing Forestry University, Nanjing, Jiangsu, P.R.

China, 210037; * Corresponding author: zhangwenfu542697@163.com

\section{INTRODUCTION}

Over the past half century, as an emerging material, composites have made great progress. Artificial fibers, such as carbon fiber and glass fiber, have been widely used in aerospace, transportation, wind power, and other fields (Chen and Ueharo 2020; Zhang et al. 2020a). However, due to the environmental pollution of these materials, people have begun to use green natural fiber as the reinforcement of composites (Liu et al. 2012; Depuydt et al. 2019; Zhang et al. 2020b). Bamboo fiber-reinforced epoxy resin composites have excellent mechanical strength and fatigue resistance, which makes them an ideal substitute for glass fiber reinforced composites in various fields (Kaur et al. 2017; Song et al. 2017). Bamboo fiber reinforced thermosetting resin composites are limited by the length and separation of the bamboo fibers, so they are generally fabricated by hot pressing (HP), cold briquetting, hand lay-up, and resin transfer molding (RTM). Many researchers have studied the hygroscopic aging properties, the mechanical properties, and the fiber surface treatment of bamboo fiber composites prepared by these molding methods (Kim et al. 2013; Zakikhani et al. 2014; Khan et al. 2017; Huang and Young 2019). To realize the practical application of bamboo fiber composites, an advanced preparation technology is needed for 
the continuous production of bamboo fiber composites. The advanced preparation technology can increase the convenience and speed of the bamboo fiber composite preparation process.

Filament winding is an advanced technology for the fabrication of highperformance composites (Kang et al. 2017). Filament winding can achieve pressure-free fabrication of non-planar composites with complicated shapes using resin-immersed twisting fibers. The composites prepared by the filament winding processing (FWP) exhibit unique process advantages compared with the composites prepared by compression molding and RTM. First, fiber staggering and stress concentration at short fiber ends are avoided; second, the composite structure can be customized according to forces and application conditions; third, the composite shows good integrity and application safety due to limited quantities of components and stress points on the connection parts; fourth, automatic processing with high efficiency and good reliability can be readily achieved; and fifth, the manufacturing cost is low. The raw materials and filament winding parameters can be determined according to the design requirements so that the product exhibits good performance and economic values (Shrigandhi and Kothavale 2021).

The development of bamboo fiber composites made by FWP with controllable performance characteristics can help to bring bamboo fiber composites to commercialization in irregular shell composites. The bamboo fiber composites made by FWP may be substituted for glass or carbon fiber composites. The lightweight and high modulus structure and recyclability of bamboo fiber composites play a key role in their applications in irregular shells in construction and automobile parts, anti-collision buffer shells in sports equipment, packaging, electrical products, and storage shells.

In this study, a thermosetting epoxy resin system (epoxy resin YD127 and solidification agent EC201) was used as the resin matrix, and bamboo fibers of different sizes were used as the reinforcing materials. The performance of the bamboo fiber composites was analyzed and compared to bamboo fiber composites prepared by FWP, HP and RTM to clarify the effects of the molding process on the performance of the bamboo fiber composites.

\section{EXPERIMENTAL}

\section{Materials}

The short bamboo fiber (SBF) (average length: $2.54 \mathrm{~cm}$; average diameter: 0.25 $\mathrm{mm}$ ) and long bamboo fiber (LBF) (average length: $23.97 \mathrm{~cm}$; average diameter: $0.5 \mathrm{~mm}$ ) that were used in this study were purchased from Fujian Haibosi Chemical Technology Co., Ltd (China). The twisted bamboo fiber (TBF) was self-prepared. For preparation of the twisted bamboo fiber, the bamboo fiber was fed into the acupuncture machine, so that the bamboo fiber could become the bamboo fiber mat in the form of sheets. Then the bamboo fiber mat was placed into the fiber orientation narrowing machine, and the wide width of the bamboo fiber mat was gathered to orient the bamboo fiber strip. Finally, the bamboo fiber strips were processed into the twisted bamboo fibers by the fiber twisting machine driven by the forward force of the spiral.

The epoxy resin system, which consisted of epoxy resin (YD127) and solidification agent (EC201), was purchased from Nan Ya Electronic Materials (Kunshan) Co., Ltd (China). The experimental equipment included an Instron universal testing machine (5582, Norwood, MA, USA), a field emission environment scanning electron microscope (FEG- 
ESEM) (XL30; Thermo Fisher Scientific, Hillsboro, OR, USA), and a dynamic mechanical analyzer (DMA) (Q800; Mettler Toledo, New Castle, DE, USA).

\section{Composites Preparation}

For the FWP, a Naval Ordnance Laboratory (NOL) ring, which is a circumferential winding fiber reinforced sample, was fabricated according to the ASTM standard D 229116 (2016), as seen in Fig. 1a.

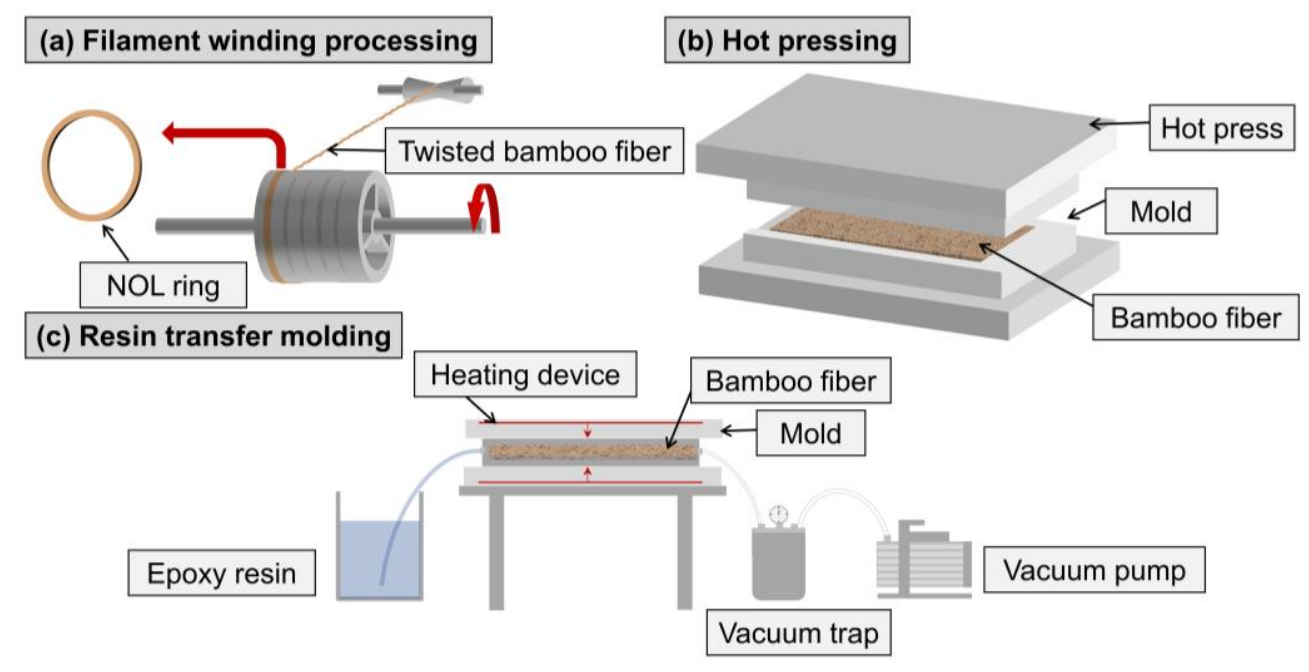

Fig. 1. Preparation of the bamboo fiber composites by a) FWP, b) HP, and c) RTM

The HP of the fiber composites was achieved using a hot-pressing machine (hot in, cold out) and a fixed-thickness frame mold with a thickness of $5 \mathrm{~mm}$ Fig. 1b. The HP parameters involved a hot-pressing pressure of $2 \mathrm{MPa}$, a hot-pressing time of $2 \mathrm{~min} / \mathrm{mm}$, and a hot-pressing temperature equal to $120{ }^{\circ} \mathrm{C}$. During the pressure release, the temperature of the hot-pressing machine was $50{ }^{\circ} \mathrm{C}$. First, the resin solution was prepared with an epoxy resin YD127 to solidification agent EC201 ratio of 4:1. Then, the SBF, LBF, and TBF were weighed. The fibers and resin were inserted into the mold in an alternative manner (fiber-resin-fiber-resin-fiber), followed by pressing and heating solidification. Afterwards, the cooling water valve of the hot-pressing machine was opened, and the pressure was relieved when possible. Finally, the assembly was removed and left untouched for 7 days before it was subjected to the post treatment and performance testing. The designed density and resin content of the sample were $1 \mathrm{~g} / \mathrm{cm}^{3}$ and $50 \%$, respectively.

For the RTM, the bamboo fiber composites were fabricated using a vacuum adhesive injector with a vacuum level of $0.09 \mathrm{MPa}$, an injection pressure of $0.2 \mathrm{MPa}$, a solidification temperature of $120{ }^{\circ} \mathrm{C}$, and a solidification rate of $2 \mathrm{~min} / \mathrm{mm}$. The mold was naturally cooled to room temperature, and the panel was removed. Figure 1c illustrates the vacuum-assisted RTM equipment and process. First, the resin solution was prepared with an epoxy resin YD127 to solidification agent EC201 ratio of 4:1. The resin solution was then injected into the adhesive injector. The fibers were uniformly distributed in the mold, which had been closed and evacuated. By removing air in the vascular bundle fibers, the porosities of the final products were reduced. Afterwards, the resin was injected into the mold by an adhesive injector, and the resin content was controlled at $50 \%$. Upon complete heating solidification, the mold was naturally cooled to room temperature, and the sample 
was removed and left untouched for 7 days before the post treatment and performance testing. The designed density and resin content of the sample were $1 \mathrm{~g} / \mathrm{cm}^{3}$ and $50 \%$, respectively.

Samples for shear performance, bending performance and DMA test were cut with a circular saw. Before the test, all samples were kept at a constant temperature of (23 $\pm 2)^{\circ} \mathrm{C}$ and relative humidity of $(50 \pm 10) \%$ for at least 7 days.

\section{Physical and Mechanical Properties Test}

The density of the samples was tested based on the GB/T standard 1463 (2005). Each group contained 6 samples. The shear and bending performance of the samples were tested based on the ASTM standard D2344-16 (2016) and the ISO standard 14125 (1998), with an Instron 5848 mechanical testing machine using a $2 \mathrm{kN}$ sensor and three-point bending fixture. For the shear and bending performance test, the span was four and sixteen times the thickness of the sample, respectively, and the diameter of the loading and supporting fixtures were 4 and $10 \mathrm{~mm}$, respectively. In the testing process, each group contained 12 samples, which were placed on the support with the convex surface upward. The loading speed was adjusted to ensure sample failure within 60 to $90 \mathrm{~s}$.

\section{Dynamic Thermomechanical Performance Test}

The interfacial performance of the composite samples was analyzed by thermodynamic mechanical analysis. The three-point bending fixture was applied in the analysis because it does not produce the holding effect and it is suitable for harder samples and characterizing the tensile and compression loss characteristics of the composites with laminated structures. The specific testing parameters included the three-point bending loading mode, where the temperature ranged from room temperature to $240{ }^{\circ} \mathrm{C}$, the heating rate was $3^{\circ} \mathrm{C} / \mathrm{min}$, the amplitude was $15 \mu \mathrm{m}$, and the frequencies were $1 \mathrm{~Hz}, 4 \mathrm{~Hz}, 7 \mathrm{~Hz}$, and $10 \mathrm{~Hz}$, respectively. The sample size was $60 \mathrm{~mm} \times 4 \mathrm{~mm} \times 3 \mathrm{~mm}$, and each group was tested three times.

\section{Analysis of the frequency dependence of the storage modulus}

The $k$ value was calculated according to Eq. 1 as the correlation coefficient of the frequency dependence of the storage modulus,

$$
E^{\prime}=k \lg f+b
$$

where $E^{\prime}$ is storage modulus (MPa), $f$ is the frequency $(\mathrm{Hz})$, and $k$ and $b$ are constants.

\section{Analysis of the relationship between the glass transition temperature and frequency}

The apparent activation energy was calculated according to Eq. 2, which was obtained by transforming the Arrhenius formula and used to characterize the relationship between the glass transition temperature and frequency,

$$
E_{a}=-R \cdot \frac{d(\ln f)}{d\left(\frac{1}{T_{g}}\right)}
$$

where $E_{a}$ is the glass transition apparent activation energy $(\mathrm{kJ} / \mathrm{mol}), R$ is the universal gas constant, $\left(8.314 \times 10^{-3} \mathrm{~kJ} /(\mathrm{mol} \cdot \mathrm{K})\right), f$ is the frequency $(\mathrm{Hz})$, and $T_{g}$ is the glass transition temperature of the fiber composites at frequency $f$. 


\section{RESULTS AND DISCUSSION}

\section{Physical and Mechanical Performance}

As shown in Table 1, the shear strengths of the TBF composites followed the sequence: FWP > HP > RTM. The FWP-TBF composites, which were aligned in a parallel/regular arrangement, exhibited no fiber overlap or mismatch. In the HP-TBF and RTM-TBF composites, the fibers were placed manually so that they were loosely aligned in a parallel arrangement. However, the fibers were exposed to bending deformations due to intrinsic stresses, which changed the fiber arrangement and reduced the binding strength of the fiber interfaces. The lowest shear strength of the RTM-TBF composites may be attributed to the disturbances in the fiber alignment caused by the flowing resin.

Table 1. Performance of Bamboo Fiber Composites Made by Different Molding Processes

\begin{tabular}{|c|c|c|c|c|c|c|}
\hline \multicolumn{2}{|c|}{ Index } & $\begin{array}{c}\text { Density } \\
\left(\mathbf{g} / \mathbf{c m}^{3}\right)\end{array}$ & $\begin{array}{c}\text { Shear } \\
\text { Strength } \\
(\mathrm{MPa})\end{array}$ & $\begin{array}{c}\text { Bending } \\
\text { Strength } \\
(\mathbf{M P a})\end{array}$ & $\begin{array}{c}\text { Bending } \\
\text { Modulus } \\
(\mathrm{MPa})\end{array}$ & $\begin{array}{c}\text { Surface } \\
\text { Bending } \\
\text { Strain } \\
(\%)\end{array}$ \\
\hline \multirow{3}{*}{ FWP } & FWP-TBF & 0.974 & 18.31 & 105.41 & 3523.24 & 2.03 \\
\hline \multirow{3}{*}{ HP } & HP-SBF & 1.148 & 10.29 & 78.69 & 5624.13 & 6.27 \\
\cline { 2 - 7 } & HP-LBF & 1.135 & 10.43 & 88.10 & 5727.09 & 7.55 \\
\cline { 2 - 7 } & HP-TBF & 1.164 & 14.81 & 138.57 & 9763.58 & 7.51 \\
\hline \multirow{3}{*}{ RTM } & RTM-SBF & 1.114 & 11.06 & 71.89 & 4249.71 & 7.45 \\
\cline { 2 - 7 } & RTM-LBF & 1.111 & 10.85 & 72.06 & 5428.38 & 6.49 \\
\cline { 2 - 7 } & RTM-TBF & 1.147 & 9.10 & 160.67 & 9900.63 & 9.04 \\
\hline
\end{tabular}

The bending performances of the bamboo fiber composites by different molding processes followed the sequence: $\mathrm{RTM}>\mathrm{HP}>\mathrm{FWP}, \mathrm{TBF}>\mathrm{LBF}>\mathrm{SBF}$. In the composites that were prepared by RTM, the inter-fiber pores were filled by resin and the composites had no structural defects. Compared with HP, the bending strength of the RTM-LBF composites was not significantly higher than the RTM-SBF composites, which was mainly due to the fact that the bending strength of bamboo fiber composites prepared by RTM was not only related to the bamboo fiber properties, but also had a greater relationship with the resin-fiber interface properties, with a larger gap between long bamboo fibers in the mold, a shorter resin injection time, and a poorer resin impregnation effect on the long bamboo fibers, while the short bamboo fibers were closer to each other, the resin injection time was longer, and the resin impregnation effect was good. The bamboo fiber properties and the interfacial properties jointly affected the bamboo fiber composites prepared by RTM. In the composites that were prepared by FWP, there was little external pressure and the porosity was high, which created a high risk of compression bending cracking and a low surface bending strain. Among the composites by one specific molding process but using different fibers, the TBF composites exhibited optimized bending performance, demonstrating that the twisting fibers can effectively enhance the overall performance of the composites.

Figure 2 shows the micro-morphologies of the composites made with different molding processes. The composites that were generated by FWP were characterized by a 
high porosity and the composites that were generated by HP were exposed to adhesive absence, resulting in compression deformation of fibers and significant densification as a result. The composites that were prepared by vacuum-assisted RTM seemed to exhibit optimized performance with low porosity and strong binding of the fibers and resin (Xia et al. 2015).
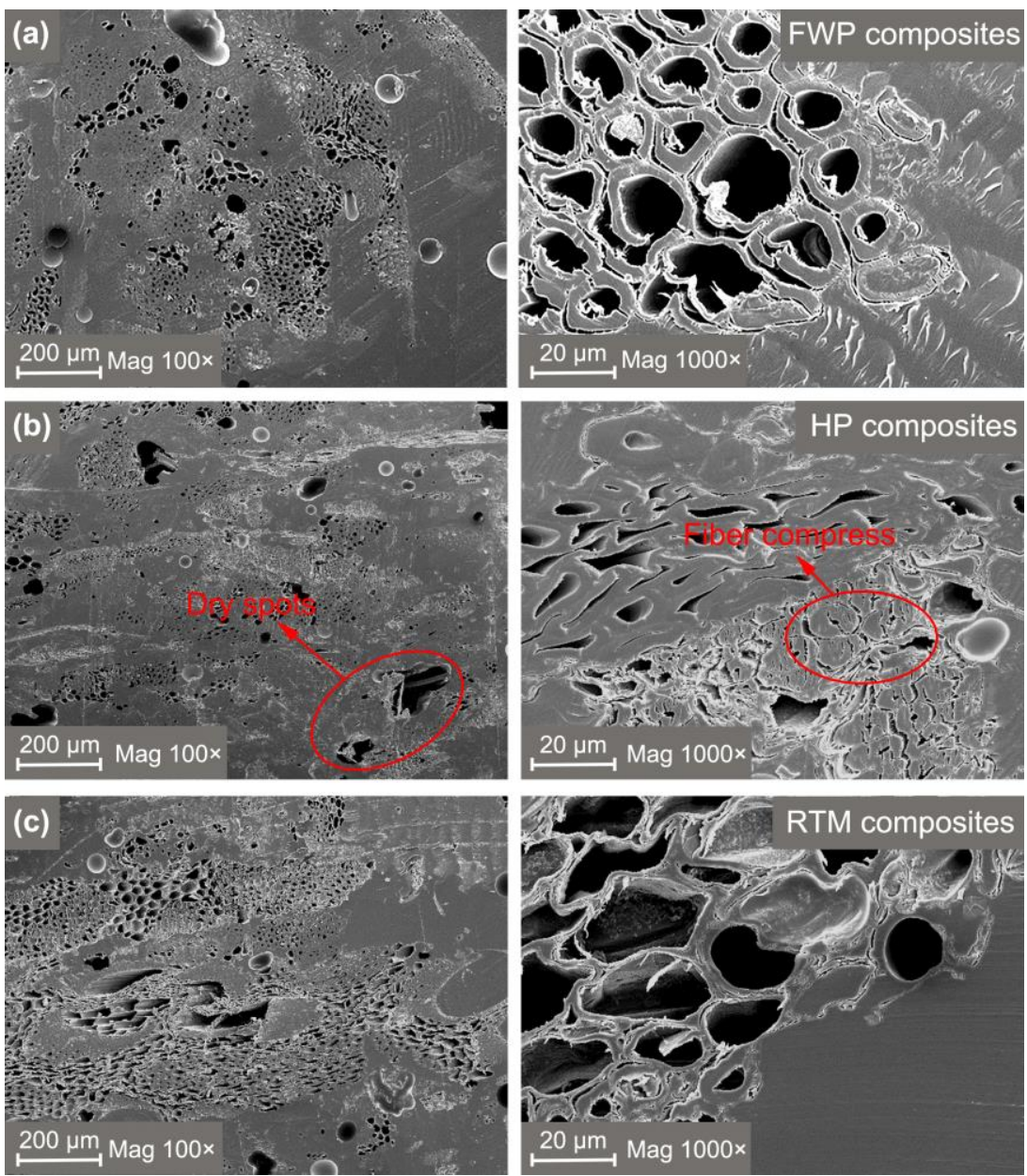

Fig. 2. Micro-morphologies of the bamboo fiber composites that were prepared by different molding processes: a) FWP composites, b) HP composites, and c) RTM composites
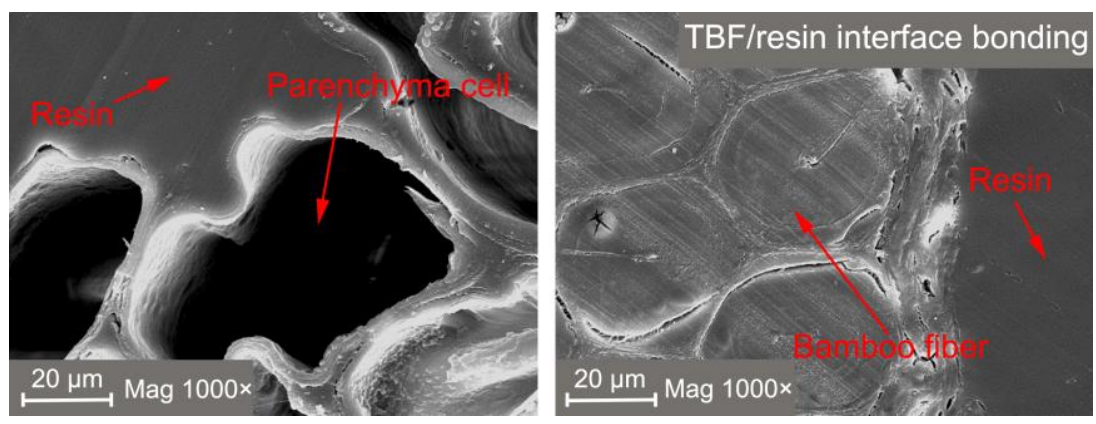

Fig. 3. Twisted bamboo fiber/resin interfaces 
In the FWP-TBF composites, the TBF were coated by resin. The resin was unable to penetrate the fibers, so it incompletely filled the surface of the vascular fiber bundles (Fig. 3). The regular alignment of the fibers in the TBF composites guaranteed a high shear strength and a strong interfacial binding strength.

\section{Dynamic Thermomechanical Performance}

Dynamic thermomechanical performance under a single frequency

As shown in Fig. 4, the storage modulus of the bamboo fiber composites decreased as the temperature increased. Among the composites made by the three molding processes, the TBF composites exhibited the largest storage modulus. The storage moduli of the composites by the different molding processes followed the sequence: RTM > HP > FWP. Moreover, the storage modulus of the FWP-TBF composites was higher than that of the FWP-SBF and FWP-LBF composites, which demonstrated good overall performance of the TBF composites. In the absence of external pressure, the bamboo fiber composites by FWP exhibited good rigidity and thermal stability.

The loss peak areas of the FWP-TBF, HP-TBF, and RTM-TBF composites were calculated to be 39800,31900 , and $36600 \mathrm{MPa} \cdot \mathrm{min}$, respectively. Herein, the FWP-TBF composites exhibited the largest loss peak area, which indicated good overall interfacial properties of composites by the FWP. This can be attributed to the regular alignment of fibers in composites by the FWP. However, the composites that were prepared by HP and RTM had relatively high porosity values.
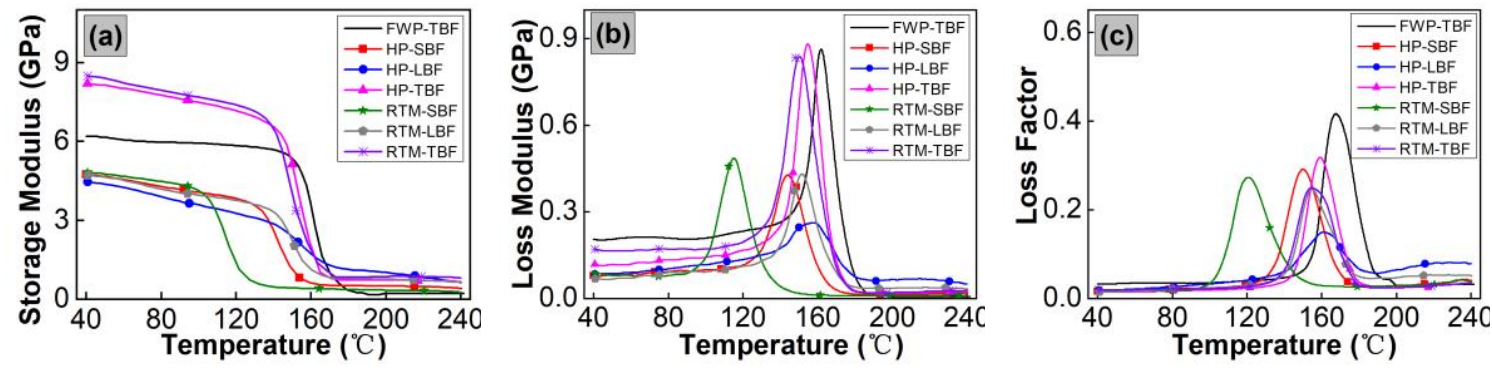

Fig. 4. DMA curves of the bamboo fiber composites under a single frequency: The a) storage modulus, b) loss modulus, and c) loss factor

Dynamic thermomechanical performance under multiple frequencies

As shown in Figs. 5 and 6, the effects of the temperature and frequency on HP-TBF composites were consistent with those on the FWP-TBF composites. The temperature and the frequency had large effects on the composite rigidity.
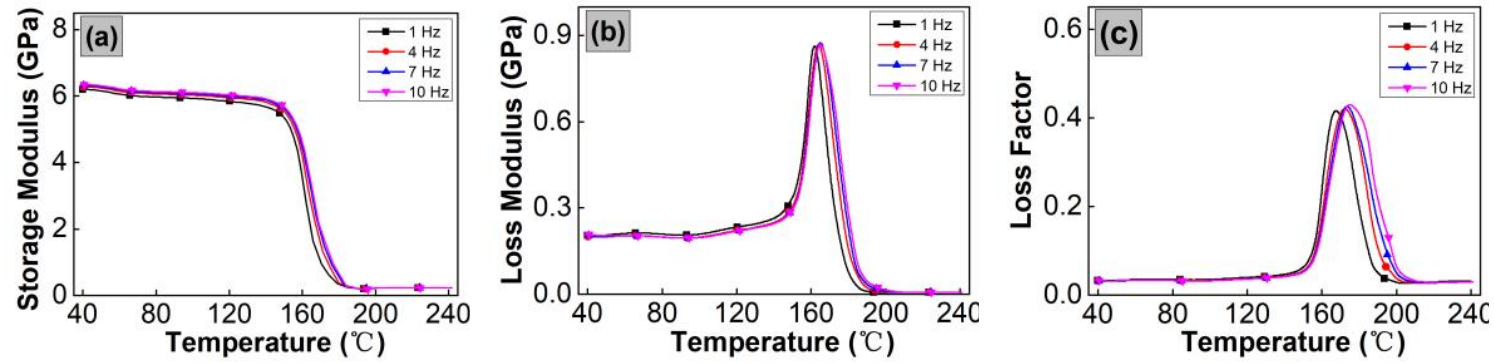

Fig. 5. DMA curves of the FWP-TBF composites under multiple frequencies: The a) storage modulus, b) loss modulus, and c) loss factor 

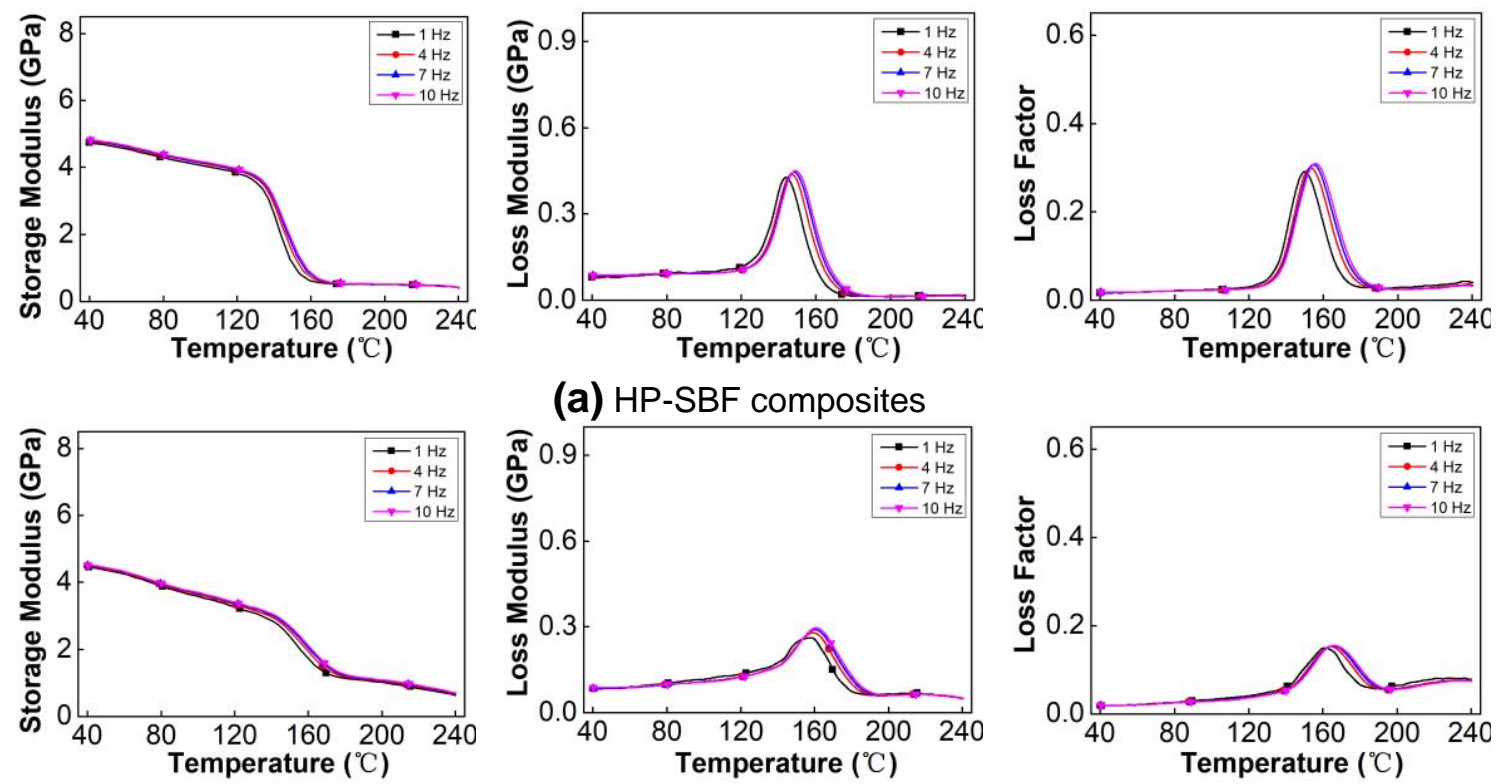

(a) HP-SBF composites
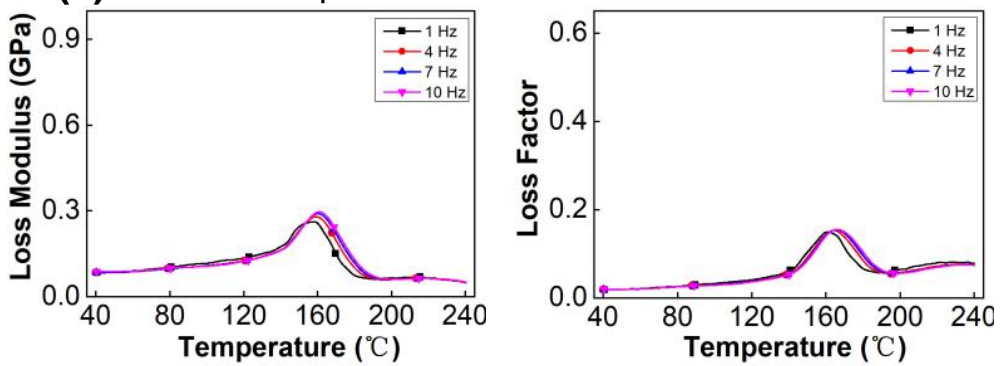

(b) HP-LBF composites
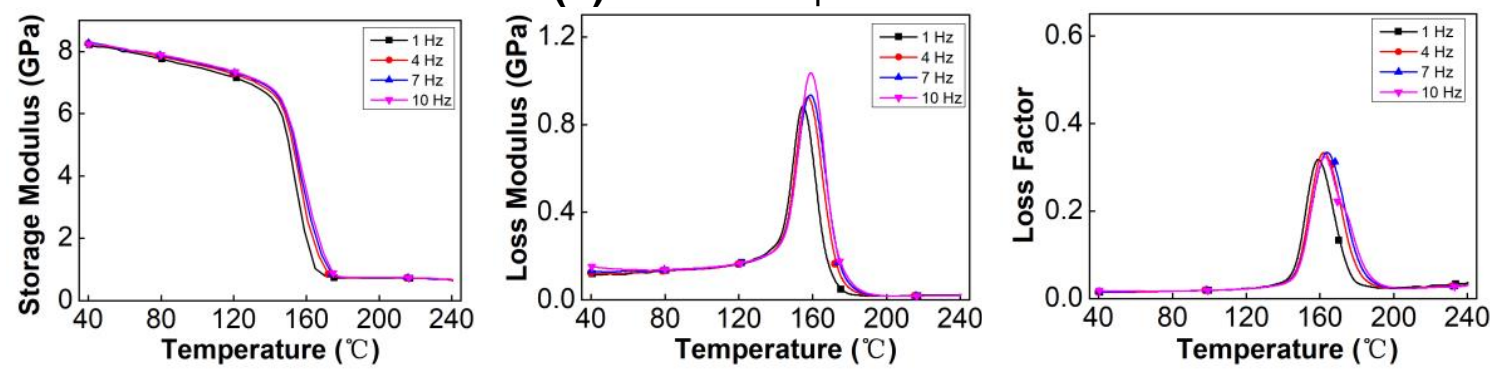

(c) HP-TBF composites

Fig. 6. Dynamic thermomechanical performance of the bamboo fiber composites by HP under different frequencies: The a) HP-SBF, b) HP-LBF, and c) HP-TBF composites.

As shown in Fig. 7, the effects of the temperature and the frequency on the RTMTBF composites were consistent with those of the FWP-TBF composites. The temperature and frequency both had a large effect on the composite rigidity.

As shown in Fig. 8, the storage moduli of the bamboo fiber composites increased as the frequency increased. Among all the TBF composites, the FWP-TBF and RTM-TBF samples exhibited the highest and lowest glass transition temperatures, respectively.

The glass transition activation energies of the composites were calculated based on the relationship of the glass transition temperature and the frequency. As shown in Fig. 9, the glass transition activation energies of the FWP-TBF, HP-TBF, and RTM-TBF composites were 508, 737, and $748 \mathrm{~kJ} / \mathrm{mol}$, respectively. The low glass transition activation energy of the FWP-TBF composite indicated a good fiber/resin interface. 

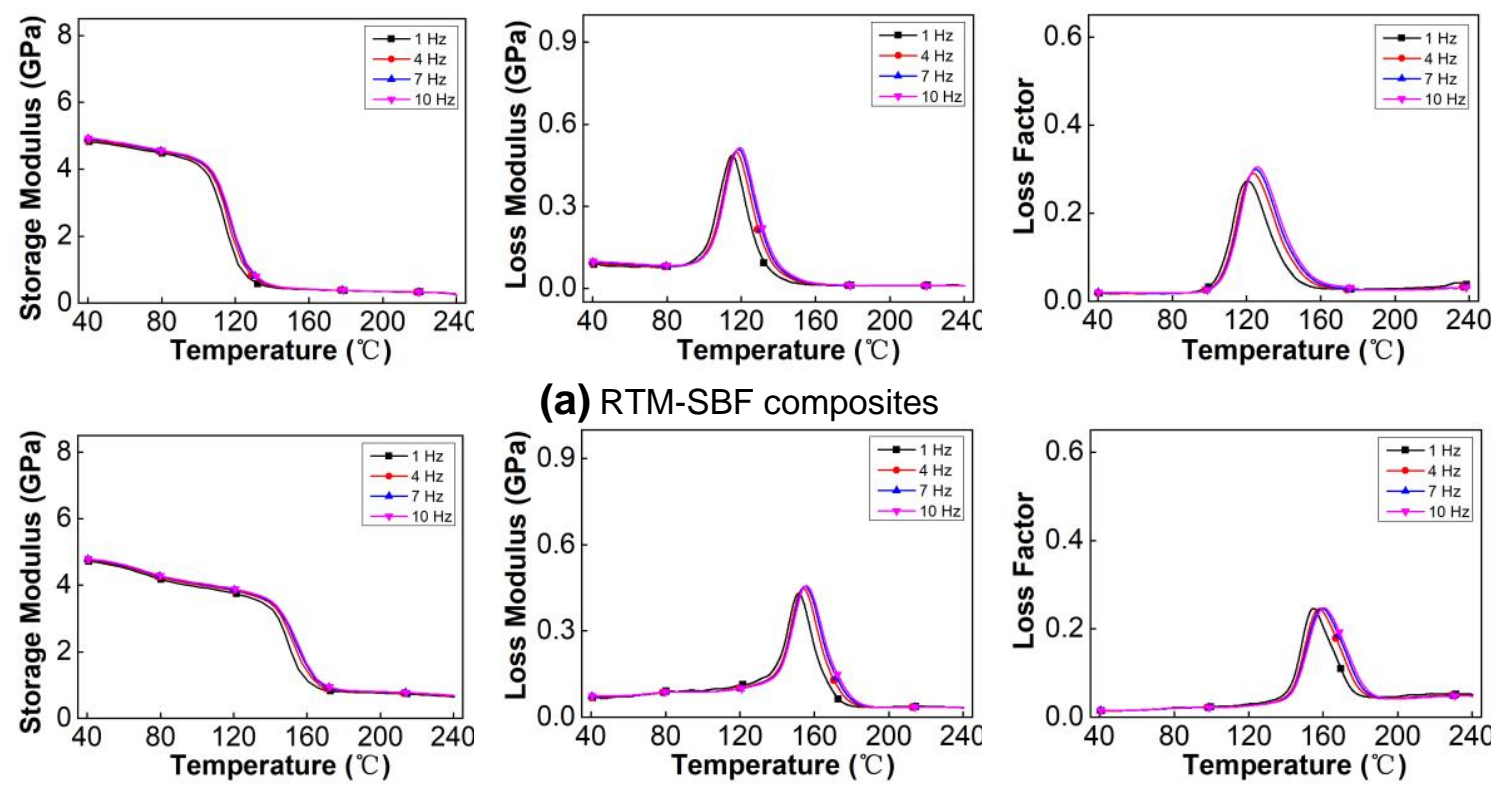

(a) RTM-SBF composites
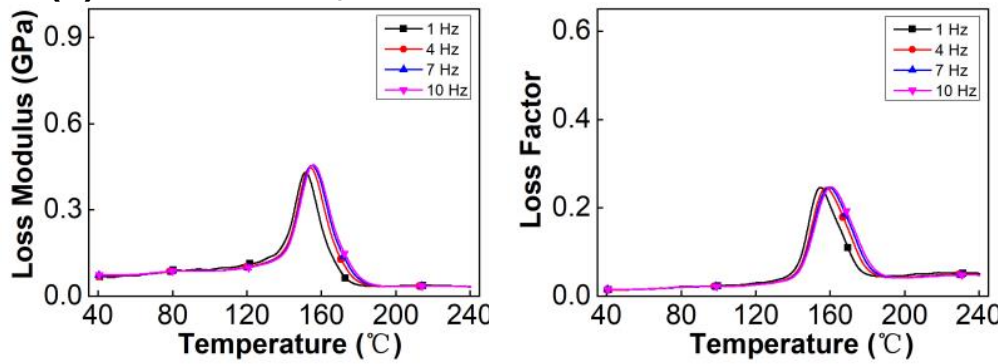

(b) RTM-LBF composites
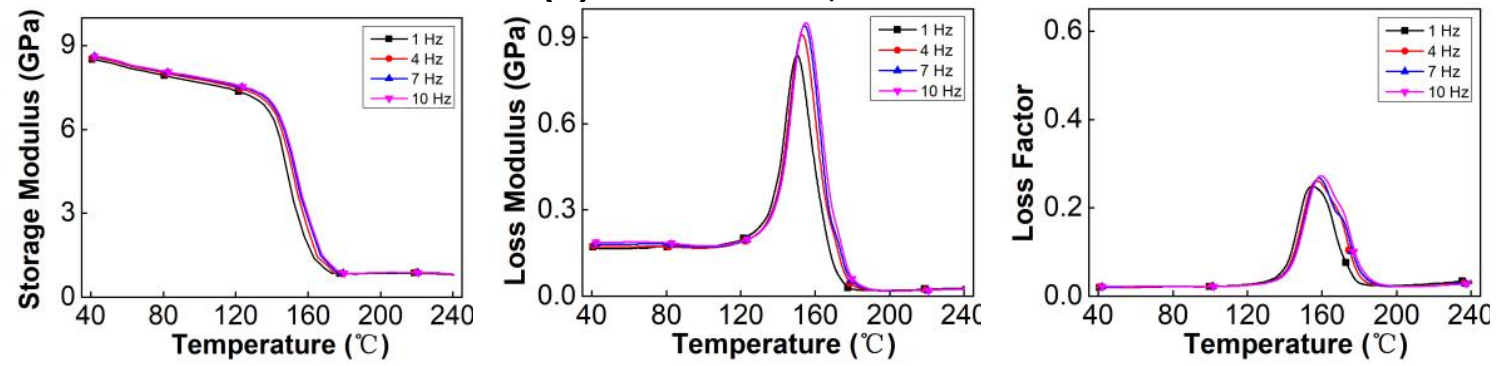

(c) RTM-TBF composites

Fig. 7. Dynamic thermomechanical performance of the bamboo fiber composites by RTM under different frequencies: The a) RTM-SBF, b) RTM-LB, and c) RTM-TBF composites

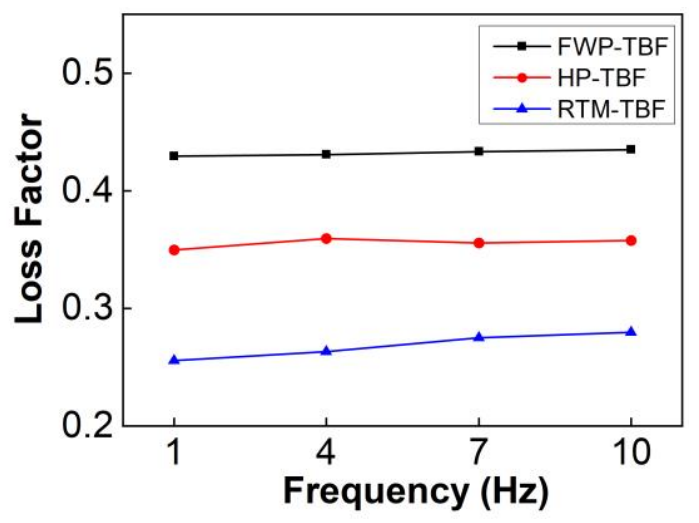

(a) Loss factor vs. frequency

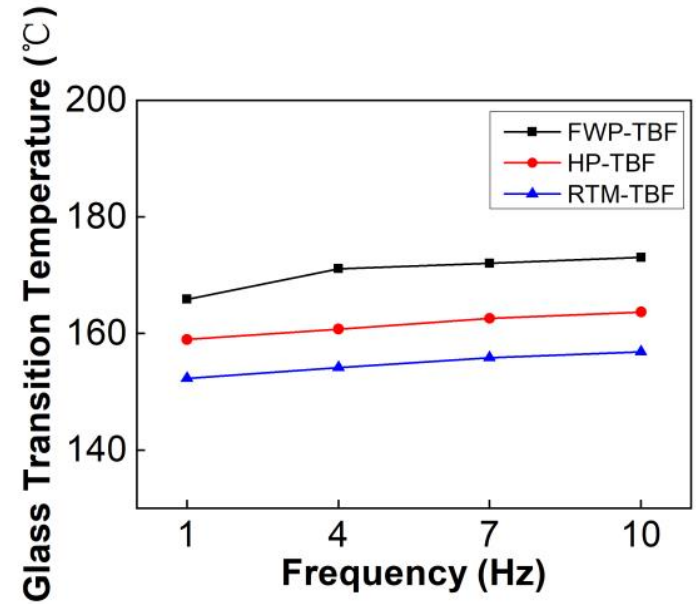

(b) Glass transition temperature vs. frequency

Fig. 8. Loss factor and the glass transition temperature of the bamboo fiber composites under different frequencies 


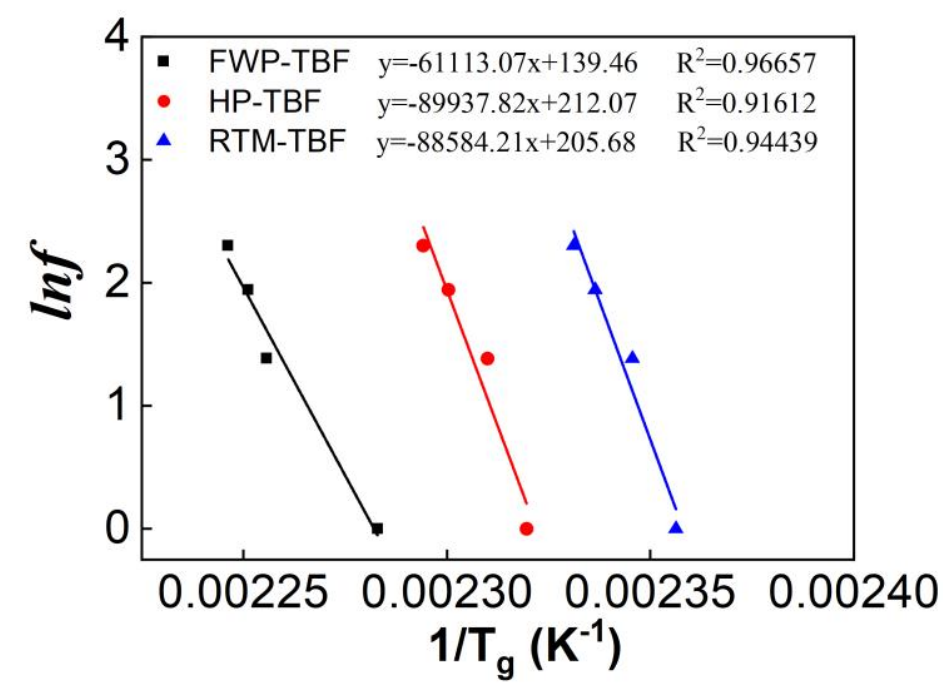

Fig. 9. Apparent activation energy of the bamboo fiber composites by different molding processes

\section{CONCLUSIONS}

1. Bamboo fiber/epoxy resin composites with stabilized performances were fabricated using bamboo fibers of different sizes. The mechanical performances, especially the bending strength, of these composites were found to be positively related to the bamboo fibers size. The filament winding processing (FWP) method can improve the overall interfacial properties of the composites, thereby clearly enhancing the shear strength.

2. The FWP method can deliver better dynamic thermomechanical performance compared with that of hot pressing (HP) and resin transfer molding (RTM). The bamboo fiber composites that were made by FWP presented good rigidity, thermal stability, and interface properties.

3. The FWP mechanism of the bamboo fiber composites involved resin immersion and the alignment of TBF upon resin immersion. The TBF were coated by resin, which was not able to enter the internal tubes or the parenchyma tissues of the TBF. Then, the TBF were aligned by winding equipment. After heated solidification of the resin, considerable bubble pores were distributed on both sides of the TBF and remained fixed. In this way, fiber/fiber, fiber/resin, and resin/resin circumferential twisting molding were achieved.

4. Preparation of bamboo fiber/epoxy resin composites using TBF can achieve both highperformance fiber composites and application of bamboo fibers in composites by FWP.

\section{ACKNOWLEDGMENTS}

This research was supported by the Zhejiang Provincial Forestry Science and technology cooperation project (No. 2020SY09) and the Zhejiang Provincial Research Institutes special project (No. 2020F1065-3). The constructive comments from the anonymous reviewers are greatly appreciated. 


\section{REFERENCES CITED}

ASTM D2291-16 (2016). "Standard practice for fabrication of ring test specimens for glass-resin composites," ASTM International, West Conshohocken, PA.

ASTM D2344-16 (2016). "Standard test method for short-beam strength of polymer matrix composite materials and their laminates," ASTM International, West Conshohocken, PA.

Chen, Y. L., and Ueharo, S. (2020). "Application of glass fiber reinforced composite materials in construction engineering," Key Engineering Materials 852, 199-208. DOI: $10.4028 / w w w . s c i e n t i f i c . n e t / K E M .852 .199$

Depuydt, D. E. C., Sweygers, N., Appels, L., Ivens, J., and van Vuure, A. W. (2019). "Bamboo fibres sourced from three global locations: A microstructural, mechanical and chemical composition study," Journal of Reinforced Plastics and Composites 38(9), 397-412. DOI: 10.1177/0731684419828532

GB/T 1463 (2005). "Test methods for density and relative of fiber reinforced plastics," Standardization Administration of China, Beijing, China.

Huang, J.-K., and Young, W.-B. (2019). "The mechanical, hygral, and interfacial strength of continuous bamboo fiber reinforced epoxy composites," Composites Part B: Engineering 166, 272-283. DOI: 10.1016/j.compositesb.2018.12.013

ISO 14125 (1998). "Fibre-reinforced plastic composites - Determination of flexural properties," International Organization for Standardization, Geneva, Switzerland.

Kang, C., Shi, Y., He, X., Yu, T., Deng, B., Zhang, H., Sun, P., and Zhang, W. (2017). "Multi-response optimization of T300/epoxy prepreg tape-wound cylinder by grey relational analysis coupled with the response surface method," Materials Research Express 4(9), 095301. DOI: 10.1088/2053-1591/aa82f5

Kaur, N., Saxena, S., Gaur, H., and Goyal, P. (2017). "A review on bamboo fiber composites and its applications," International Conference on Infocom Technologies and Unmanned Systems 18-20, 843-849.

Khan, Z., Yousif, B. F., and Islam, M. (2017). "Fracture behaviour of bamboo fiber reinforced epoxy composites," Composites Part B: Engineering 116, 186-199. DOI: 10.1016/j.compositesb.2017.02.015

Kim, H., Okubo, K., Fujii, T., and Takemura, K. (2013). "Influence of fiber extraction and surface modification on mechanical properties of green composites with bamboo fiber," Journal of Adhesion Science and Technology 27(12), 1348-1358. DOI: 10.1080/01694243.2012.697363

Liu, D., Song, J., Anderson, D. P., Chang, P. R., and Hua, Y. (2012). "Bamboo fiber and its reinforced composites: Structure and properties," Cellulose 19(5), 1449-1480.

DOI: $10.1007 / \mathrm{s} 10570-012-9741-1$

Shrigandhi, G. D., and Kothavale, B. S. (2021). "Biodegradable composites for filament winding process," Materials Today: Proceedings 42, 2762-2768. DOI: 10.1016/j.matpr.2020.12.718

Song, K., Ren, X., and Zhang, L. (2017). "Bamboo fiber-polymer composites: overview of fabrications, mechanical characterizations and applications," In: Green

Biocomposites. Green Energy and Technology, M. Jawaid, M. Salit, and O. Alothman (eds.), Springer, Cham, Switzerland, pp. 209-246. DOI: 10.1007/978-3-319-493824_10

Xia, C., Shi, S. Q., Cai, L., and Hua, J. (2015). "Property enhancement of kenaf fiber composites by means of vacuum-assisted resin transfer molding (VARTM)," 
Holzforschung 69(3), 307-312. DOI: 10.1515/hf-2014-0054

Zakikhani, P., Zahari, R., Sultan, M. T. H., and Majid, D. L. (2014). "Extraction and preparation of bamboo fibre-reinforced composites," Materials \& Design 63, 820828. DOI: 10.1016/j.matdes.2014.06.058

Zhang, J., Chevali, V. S., Wang, H., and Wang, C.-H. (2020a). "Current status of carbon fibre and carbon fibre composites recycling," Composites Part B: Engineering 193, 108053. DOI: 10.1016/j.compositesb.2020.108053

Zhang, Z., Cai, S., Li, Y., Wang, Z., Long, Y., Yu, T., and Shen, Y. (2020b). "High performances of plant fiber reinforced composites - A new insight from hierarchical microstructures," Composites Science and Technology 194, 108151. DOI:

10.1016/j.compscitech.2020.108151

Article submitted: July 19, 2021; Peer review completed: September 5, 2021; Revised version received and accepted: September 11, 2021; Published: September 20, 2021. DOI: 10.15376/biores.16.4.7416-7427 